\title{
Heartburn in Belgium: prevalence, impact on daily life, and utilization of medical resources
}

\author{
Edouard Louis ${ }^{\mathrm{a}}$, Danny DeLooze ${ }^{\mathrm{b}}$, Pierre Deprez ${ }^{\mathrm{c}}$, Martin Hiele ${ }^{\mathrm{d}}$, Daniel Urbain ${ }^{\mathrm{e}}$, Paul Pelckmans ${ }^{\mathrm{f}}$, Jacques \\ Devière $^{9}$ and Michel Deltenre ${ }^{\mathrm{h}}$ \\ ${ }^{a}$ Gastroenterology Department, CHU of Liège, ${ }^{b}$ GastroanteroIogy Department, UZ Gent, ${ }^{c}$ Gastroenterology Department, Clinique \\ universitaire St Luc, Brussels, ${ }^{d}$ Gastroenterology Department, UZ Leuven, ${ }^{e}$ Gastroenterology Department, AZ VUB, Brussels, \\ ${ }^{f}$ Gastroenterology Department AZ Antwerp, ${ }^{g}$ Gastroenterology Department, Hôpital Erasme, Brussels, and ${ }^{h}$ Gastroenterology Department \\ Hôpital Brugmann, Brussels, Belgium
}

Background Gastro-oesophageal reflux disease (GORD) is a frequently occurring disease that may be considered a public health issue, particularly in developed countries. The specificity of heartburn for the diagnosis of GORD is good. Our aim was to define the prevalence of heartburn in Belgium, characterizing both its impact on everyday life and the ensuing use of medical resources.

Methods Two thousand people living in Belgium, selected randomly after stratification, were interviewed face to face. The main question in the questionnaire used in this interview concerned the presence over the previous 12 months of a burning sensation in the epigastric and/or retrosternal region. This was followed by 21 secondary questions on the characteristics of the population studied, the impact of heartburn on everyday life, and the medical resources used.

Results Twenty-eight per cent of the population interviewed reported heartburn. This symptom was present at least once a week In $42 \%$ of sufferers. Heartburn was more frequent in women than men $(P<0.05)$ and was not distributed uniformly throughout the various regions of the country $(P<0.05)$. Seventy-seven per cent of the people with heartburn found that it had a significantly negative impact on their daily lives (in $27 \%$, this effect was strong). Heartburn associated with a substantial negative impact on daily life was characterized by a higher frequency of symptoms $(P<0.0001)$, a longer duration of the problem $(P=0.006)$, and the presence of pain $(P$ $<0.0001)$ and anxiety $(P<0.0001)$. Fifty-six percent of individuals with heartburn had already sought medical advice, $45 \%$ had undergone an upper-gastrointestinal tract endoscopy, and 59\% were taking medications. Among patients complaining that heartburn had a substantial negative effect on their everyday lives, $21.6 \%$ had not sought medical advice and $22.2 \%$ did not take any medication.

Conclusion Heartburn is very frequent in Belgium and is associated with a considerable negative impact on everyday life. It also generates a significant use of medical resources. However, among the patients complaining of a substantial negative effect on their daily lives, one-fifth (which would represent $1.5 \%$ of the Belgian population) seemed to lack appropriate care.

Keywords : epidemiology ; gastro-oesophageal reflux disease ; utilization of medical resources

\section{Introduction}

Gastro-oesophageal reflux, under certain conditions, is a physiological phenomenon in man. To define pathological gastro-oesophageal reflux disease (GORD) is not as easy as it may seem at first sight. Pathology may be considered to be present when the acid reflux is quantitatively abnormal, when oesophageal lesions are observed, or simply because indicative symptoms are present. From the patient's point of view, as soon as there are symptoms, the phenomenon may be considered pathological.

These symptoms may have repercussions on the quality of life [1,2] and may require the use of medical resources $[3,4]$. GORD is therefore not only an individual problem but also a public health issue. During recent decades, two parallel (and probably related) events have occurred: (1) the development of drugs that are very effective in the management of GORD symptoms and lesions, and (2) a dramatic increase in the number of people suffering from GORD and therefore requiring medical advice and treatment. These combined phenomena have generated a significant increase in the cost of the medical management of GORD in Western countries [5]. 
In many European countries, consensus conferences have been held and guidelines published [6,7] in order to define reasonable and affordable strategies for the management of this disease. To comply with local medical realities, these strategies must take the specificities of local epidemiology into account as well as the way the disease is coped with by local populations. Very few European epidemiological data are available [3,8-11], and only one Belgian study has been published in abstract form [12]. In the European studies, the prevalence of gastro-oesophageal reflux symptoms, mainly heartburn, ranges from 18 to $30 \%$. In Belgium, in a telephone-call study carried out on a representative sample of 3000 individuals aged over 35 years [12], 28.1\% experienced heartburn during the previous 12 months, $11.3 \%$ at least once a week, and $4.1 \%$ daily. The aim of the present study was to evaluate the prevalence of GORD symptoms in the Belgian population and their impact on daily life and the utilization of medical resources.

\section{Method}

Between 10 December and 24 December 1998, 2000 people living in Belgium were questioned about heartburn. They had been selected randomly from the entire population (8359 200) of people aged over 15 years. To provide a sample representative of the country, the selection was stratified for the 11 Belgian provinces on the basis of degree of urbanization (four degrees, from big cities to rural areas), sex, age, profession and socioeconomic level.

The selection of individuals was performed at random as follows. The country was divided into 34 entities based on 11 provinces and four degrees of urbanization. Inside these entities, a series of municipalities were chosen at random. Up to five interviews were performed in each municipality according to its size. In each municipality, habitations were selected at random for these interviews by a computer program choosing streets and numbers of these habitations by groups of ten interviews.

The randomly selected individuals were interviewed face co face at their homes for a maximum of 30 min by professionals not involved in healthcare: these interviewing professionals were agents from the Belgian INRA company specializing in omnibus face-to-face interviews. It would be impossible to publish the complete questionnaire as part of the paper. However, an English translation was submitted, together with the present paper, for peer reviewing and is available with the electronic version of the paper. The following is a short summary of its contents.

The questionnaire included one primary question and 21 secondary questions, with one to ten sub-questions. The primary question was about the presence or absence over the previous 12 months of a burning sensation in the epigastric or retrosternal region. It also asked whether this sensation ascended in the retrosternal region and whether, in the absence of such a symptom, the individual had been treated with medications or had undergone surgery. After this primary question, the complete interview was carried out only with those individuals who had experienced the burning sensation over the previous 12 months. The subsequent questions concerned the words used by the subjects to define their symptoms, the frequency of complaints, their duration from the onset of the problem, and possible favouring circumstances. The impact on everyday life and possible anxiety induced by the problem, as well as lifestyle changes, were also looked at. Questions were asked concerning the use of medical resources, including medical consulting and follow-up, advice from the pharmacist, upper-gastrointestinal tract endoscopy, drug treatment, and information about the surgical option. Potential risk factors, including family history, smoking habits, alcohol consumption, medications taken, stress, and body mass index (BMI) calculations, were recorded.

The consistency and completeness of the questionnaire were checked afterwards for each interview. The sample was representative when compared with the data provided by the National Institute for Statistics.

\section{Statistics}

The 2000 individuals interviewed can be considered as a representative sample of the whole Belgian population. The results are given with their $95 \%$ confidence intervals. To compare results of defined subgroups of individuals, we used Student's $t$-test or the chi-squared test as required.

\section{Results}

\section{Prevalence of heartburn}

Of the 2000 individuals interviewed, 568 (28.4\%, 95\% CI 26.4-30.4\%) had experienced heartburn during the 
previous 12 months. An additional 1.2\% had experienced it previous to this period but were symptom-free under medical treatment or after surgery. Heartburn was significantly more frequent in women $(31.1 \%, 95 \%$ CI $28.2-$ $34 \%)$ than men $(25.6 \%, 95 \%$ CI $23.1-28.1 \% ; P<0.05)$. Prevalence of heartburn also varied in different parts of the country: it was more frequent in Wallonia (south-east) $(41.4 \%, 95 \%$ CI 37.6-45.2\%) than in Brussels (centre) $(28.1 \%, 95 \%$ CI $22.3-33.9 \%)$ or Flanders (north-west) $(20.9 \%, 95 \%$ CI 18.5-23.3\%; $P<0.05)$. There were no significant differences according to age (15-34 years: $27.5 \%, 95 \%$ CI $24.2-30.8 \%$; 35-54 years: $28.8 \%$, 95\% CI 25.3-32.3\%; > 54 years: $28.7 \%, 95 \%$ CI 25.2-32.4\%) social level (high: $25.9 \%, 95 \%$ CI 22-29.8\%; middle-high: 28.8\%, 95\% CI 24.9-32.7\%; middle-low: 27.9\%, 95\% CI 24-31.8\%; low: 30.8\%, 95\% CI 26.7-34.9\%), or urbanization (cities: $25.8 \%, 95 \%$ CI 22.1-29.5\%; towns: 29.2\%, 95\% CI 26.2-32.2\%; rural areas: $29.5 \%$, 95\% CI $25.8-33.2 \%)$.

Among the individuals complaining of heartburn, 14\% (95\% CI 11.1-16.9\%) had experienced it for less than 1 year, $25 \%$ (95\% CI $21.4-28.6 \%)$ for $1-3$ years, and 51\% (95\% CI 46.9-55.1\%) for more than 3 years $(10 \%$ no information available). The frequency of symptoms among refluxers was at least once a day in $15 \%$ (95\% CI $12.1-17.9 \%)$, at least once a week in $27 \%(95 \%$ CI $23.3-30.7 \%)$, at least once a month in $23 \%$ (95\% CI 19.5 $26.5 \%)$, and less than once a month in $32 \%$ (95\% CI 28.2-35.8\%) (3\% no data available). Ninety-five per cent (95\% CI 93.2-96.8\%) of people could mention particular circumstances for the appearance of symptoms, including after certain meals $(42 \%, 95 \%$ CI 37.9-46.1\%) and stressful contexts $(35 \%, 95 \%$ CI 31.1-38.9\%).

\section{Impact on everyday life}

Heartburn was considered as hampering everyday life in 77\% (95\% CI 73.5-80.5\%) of cases. This interference was reported as strong in $27 \%(95 \%$ CI $23.3-30.7 \%)$ of cases. Aspects of daily life that were the most hampered by heartburn were family life (49\%, 95\% CI 44.9-53.1\%), social life (30\%, 95\% CI 26.2-33.8\%), leisure time (26\%, 95\% CI 22.4-29.6\%). and professional life (24\%, 95\% CI 20.5-27.5\%). In patients for whom the interference with daily life was considerable $(n=153)$, symptoms were significantly more frequent (at least once a week: $57.9 \%, 95 \%$ CI 50.1-65.7\% v. 19.7\%, 95\% CI 12.8-26.6\%; $P<0.0001)$ and had been present for a longer period of time ( $>1$ year: $79.7 \%, 95 \%$ CI $73.3-86.1 \%$ v. $64.3 \%, 95 \%$ CI $55.9-72.7 \% ; P=0.006)$, and heartburn was associated with a sensation of pain more often $(57.2 \%, 95 \% \mathrm{CI} 49.4-65 \% \mathrm{v} .9 \%, 95 \% \mathrm{CI} 4-14 \%$ : $P<0.0001)$ and generated anxiety more often $(26.7 \%, 95 \% \mathrm{CI} 19.8-33.6 \%$ v. $0.8 \%, 95 \% \mathrm{CI} 0-2.4 \% ; P<$ $0.0001)$ than in patients whose daily lives were unaffected.

\section{Risk factors in patients for whom heartburn has a strong negative effect on daily life}

Among the subjects complaining of heartburn over the previous year, 29\% (95\% CI 25.3-32.7\%) had a family history of gastric or oesophageal disease, 34\% (95\% CI 31.1-37.9\%) were smokers (one-third smoked more than 20 cigarettes/day), 44\% (95\% CI 39.9-48.1\%) drank alcohol (one-quarter drank more than 10 units/ week), $25 \%$ (95\% CI 21.4-28.6\%) took medications for other diseases (including antihypertensives (6.5\%), antiangina pectoris drugs $(5.2 \%)$, analgesics $(4.6 \%)$, anti-inflammatory drugs $(2.0 \%)$, antidepressants $(3.9 \%)$, anxiolytics $(5.9 \%)$, and bronchospasmolytic agents $(5.9 \%)), 46 \%$ (95\% CI 41.9-50.1\%) had a BMI greater than 25 (one-fifth $>30)$, and 58\% (95\% CI 53.9-62.1\%) had a stressful life. As shown in Table 1, some of these risk factors were more frequent in subjects whose heartburn interfered seriously with their daily lives.

Table 1. Prevalence of risk factors (\% with 95\% CI) In subjects with heartburn according to Impact on daily life

\begin{tabular}{llll}
\hline \multicolumn{1}{c}{ Risk factor } & \multicolumn{1}{c}{$\begin{array}{c}\text { Severe effect }(\mathbf{a}) \\
(\boldsymbol{n}=\mathbf{1 6 3})\end{array}$} & $\begin{array}{c}\text { Slight effect }(\mathbf{b}) \\
(\boldsymbol{n}=\mathbf{2 8 8})\end{array}$ & \multicolumn{1}{c}{$\begin{array}{c}\text { No effect (c) } \\
(\boldsymbol{n}=\mathbf{1 2 8})\end{array}$} \\
\hline Positive family history & $37.3(29.6-45)$ & $30.6(25.3-35.8)$ & $15.9(9.5-22.3)^{* * *}$ \\
Smoker & $41.2(33.4-49)$ & $28.8(23.6-34)$ & $35.7(27.3-44.1)$ \\
Heavy smoker $(>20$ cigarettes/day) & $18.3(12.2-24.4)$ & $12.2(8.4-166)$ & $7.1(2.6-11.6)^{* *}$ \\
Alcohol drinkers & $38.6(32.6-44.7)$ & $42.7(37-4 \beta .4)$ & $52.4(44.8-60)^{*}$ \\
$>10$ units alcohol/week & $15(9.3-20.7)$ & $8(4.9-11.1)$ & $10.3(5-156)$ \\
Drugs for other illnesses & $33.3(25.8-40.8)$ & $29.2(23.9-34.5)$ & $8.7(3.8-13.8)^{* * *}$ \\
BMI $>$ 30 & $15(10.8-19.4)$ & $9(5.7-12.3)$ & $7.1(3.7-10.5)^{*}$ \\
Stressful life & $66(59.5-72.5)$ & $54.5(48.7-60.3)$ & $50.8(43.1-58.5)^{* *}$ \\
\hline$*<0.05$ compared with $(a) \cdot * * P<0.01$ compared with $(a) \cdot * * * P<0.0001$ compared with $(a)$. &
\end{tabular}

$* P<0.05$ compared with $(a) ; * * P<0.01$ compared with $(a): * * * P<0.0001$ compared with (a). 


\section{Utilization of medical resources}

Among the subjects complaining of heartburn, 56\% (95\% CI 51.9-60.1\%) had already consulted a physician for the problem (half of them having been followed up). Eighteen per cent (95\% CI 14.8-21.2\%) had asked for advice from a pharmacist, 45\% (95\% CI 40.9-49.1\%) had undergone an upper-gastrointestinal tract endoscopy, $48 \%$ (95\% CI 44.9-52.1\%) had changed their lifestyles, and 59\% (95\% CI 55-63\%) took medications, including antacids (44\%), $\mathrm{H}_{2}$-blockers (7.8\%), prokinetics (7.6\%) and proton-pump inhibitors (PPIs; 6.3\%). As shown in Table 2, resorting to medical aid was significantly higher in those who considered that their heartburn seriously hampered their daily lives. However, in this subgroup of individuals, 21.6\% (95\% CI 15.1-28.1\%) had not sought medical advice and $22.2 \%$ (95\% CI 15.5-28.9\%) did not take any medication. Overall, among the individuals who took medication, 93\% (95\% CI 90.5-95.5\%) were satisfied with their treatment.

Table 2. Utilization of medical resources (\% with 95\% CI) in subjects with heartburn according to impact on dally life

\begin{tabular}{llll}
\hline \multicolumn{1}{c}{ Medical resource } & \multicolumn{1}{c}{$\begin{array}{c}\text { Severe effect (a) } \\
(\boldsymbol{n}=\mathbf{1 5 3})\end{array}$} & $\begin{array}{c}\text { Slight effect (b) } \\
(\boldsymbol{n}=\mathbf{2 8 8})\end{array}$ & \multicolumn{1}{c}{$\begin{array}{c}\text { No effect (c) } \\
(\boldsymbol{n}=\mathbf{1 2 8})\end{array}$} \\
\hline Visit to physician & $78.4(71.9-84.9 !$ & $54.6(46.7-62.4)$ & $30.2(22.2-38.2)^{*}$ \\
Medical follow-up & $49.7(413-87.6)$ & $21.9(17.1-26.7)$ & $10.3(5-15.6)^{* *}$ \\
Pharmacist advice & $24.8(16-31.6)$ & $19.1(14.8-23.6)$ & $7.9(3.2-12.6)^{*}$ \\
Upper-GI endoscopy & $54.9(47-62.8)$ & $29.2(23.9-34.5)$ & $15.9(9.5-22.3)^{* *}$ \\
Several endoscopies & $25.5(18.6-32.4)$ & $14.6(10.5-18.7)$ & $10.3(5-15.6)^{*}$ \\
Lifestyle modifications & $65.4(57.9-72.9)$ & $46.9(41.1-52.7)$ & $32.5(24.3-42.7)^{* *}$ \\
Medication for GORD*** & $77.8(71.2-84.4)$ & $56.6(50.9-62.3)$ & $41.3(32.7-49.9)^{* *}$ \\
$\quad$ Antacids & $52.3(44.4-60.2)$ & $47.2(41.4-53)$ & $29.4(21.4-37.4)^{* *}$ \\
H2-blockers & $15(9.3-20.7)$ & $5.2(2.6-7.8)$ & $4.8(1.1-8.5)^{*}$ \\
PPIs & $9.8(5.1-14.5)$ & $4.2(1.9-8.5)$ & $7.1(2.6-11.6)$ \\
Prokinetics & $17.8(11.6-23.8)$ & $5.6(2.9-8.3)$ & $0 *$ \\
Other & $15(8.4-21.6)$ & $4.2(1.6-6.8)$ & $0.8(0-2.4)^{* *}$ \\
\hline
\end{tabular}

GI, gastrointestinal; GORD, gastro-oesophageal reflux disease; PPI, proton-pump inhibitors.

$* P<0.01$ compared with $(a) ; * * P<0.001$ compared with $(a) ; * * *$ some patients take several medications.

\section{Discussion}

Our study shows that in Belgium, symptoms indicating gastro-oesophageal reflux have a prevalence comparable to that reported in other European countries. In recent studies carried out in Finland [8], Sweden [9], France [3] and the UK [11], symptoms of gastro-oesophageal reflux were present in $30 \%, 25 \%, 27.1 \%$ and $18 \%$ of the populations, respectively. Regional differences may exist, but the choice of the symptom to characterize GORD and phrasing of the questionnaire are crucial and might explain some of these differences. In previous studies, various symptoms have been used, including epigastric pain, acid regurgitation and heartburn. Among these, heartburn has the highest specificity and sensitivity for the diagnosis of gastro-oesophageal reflux [13]. The specificity is probably optimal when heartburn is defined as a burning sensation starting in the epigastric or low retrosternal region and spreading upwards [13]. In the present study, 455/569 subjects complaining of heartburn described it as a sensation spreading upwards in the retrosternal region. Methodological differences may also explain variations in the results. However, although the previous study carried out in Belgium used a different method for data collection (telephone calls), it produced an almost identical result: $28 \%$ of individuals complaining of heartburn during the previous year [12].

While using the same definition for the symptoms and the same methodology in each case, our study shows that striking differences may exist between populations that arc very close geographically. It is of interest that the difference we found between the three regions of Belgium (Wallonia, Brussels, Flanders) had already been found, in almost exactly the same proportions, in the previous Belgian epidemiological study [12]. Differences in gastro-oesophageal reflux or heartburn prevalence between various populations have often been explained by lifestyle and other risk factors. The high prevalence of heartburn found among North Americans, for example, with $4-7 \%$ having heartburn daily $[14,15], 14-30 \%$ weekly $[14,15]$ and $15-44 \%$ monthly $[14,16]$, has been correlated to obesity and a particular diet. In the population with heartburn in the present study (data given in a separate part of the study), a positive family history, concomitant taking of medication for other diseases, 
including antihypertensives, anti-anginals and nonsteroidal anti-inflammatory drugs, together with a stressful lifestyle was more frequent in Wallonia than Flanders, while no differences were found for smoking habits, alcohol consumption or excess weight [17]. We also found a significant difference in the prevalence of heartburn between men and women. Heartburn was more frequent in women. This is in accordance with a French epidemiological study [3], but in other studies this frequency was either equal $[9,16]$ or higher in men $[18,19]$. In our population, risk factors, including positive family history, concomitant taking of medication, stressful lifestyle and excess weight, were more frequent among women (data not shown).

It is the intensity and consequences for everyday life, rather than simply the presence of a symptom indicating gastro-oesophageal reflux, such as heartburn, that determine the burden for the individual and the community. In this respect, we should emphasize that, in our study, $77 \%$ of individuals complaining of heartburn also complained of a significantly negative effect on their daily lives. It has been shown in previous studies that gastro-oesophageal reflux impairs the quality of life substantially [1,2,20,21]. In the population complaining of heartburn in this study (which represents, by extrapolation, almost $30 \%$ of the whole population of the country), a large proportion (27\%) reported severe disruption of their daily lives. Therefore, up to $10 \%$ of the Belgian population may be severely hampered in everyday life by heartburn. It must be emphasized that, in the present work, we did not use a strict quality-of-life measurement but rather a general appreciation by the patient. Strict evaluation of quality of life by validated questionnaires may give substantially different results. This may also be the reason why the proportion of subjects with severe impairment of daily life may seem higher than expected. Previous studies have shown that, in gastro-oesophageal reflux, impairment of quality of life was related more to the intensity of heartburn than to the presence of oesophagitis $[1,22]$. In this work, hampering of daily life by heartburn was associated with a high frequency of episodes, a painful sensation, and the anxiety that was generated. This may be compared with an earlier American study in which the quality-of-life impairment due to GORD was noted mainly in the pain and psychological health sections of the questionnaire used (SF36) $[2,21]$.

Considering the potential impact of severe heartburn on the individual's quality of life and the burden for the community, it seems useful to give the risk factors for severe heartburn. In the population for this study, individuals with a positive family history of gastric or oesophageal diseases, taking medication for other illnesses, having stressful lives, smoking heavily and being overweight (BMI > 30) were at higher risk. In a recent study, it was shown that, on the whole, GORD was not more frequent in individuals with a positive family history of GORD, except in cases of severe lesions associated with reflux, such as Barrett's oesophagus or oesophageal adenocarcinoma [19]. Our data show that not only the objective but also the subjective severity of GORD, assessed here by the impact of heartburn on everyday life, may be associated with a family history and therefore genetic and/or environmental influences. Another explanation for this familial influence could be the childhood training phenomenon, as described by some authors in irritable bowel syndrome [23]. Treatment with antihypertensives, antianginals and bronchospasmolytics, which may favour reflux [24], was found more often in individuals complaining of severe heartburn. However, these drugs are often essential for the patient, and little can be done with regard to them. Stress, smoking and excess weight are part of the lifestyle classically associated with GORD or its symptoms [25]. According to our data, these factors also seem to influence the subjective severity of GORD. Information from the patients regarding this point should certainly be part of their overall management. In previous studies, alcohol consumption was not associated with the symptoms of GORD [9]. In the population in this study, a mild alcohol intake ( $<10$ units/week) was associated with less hampering of everyday life by heartburn. The reason for this remains unclear to us and confounding factors may have been involved.

Considering its frequency and the expense of diagnostic procedures and treatment, GORD is the cause of a lot of individual and social cost in Western countries. Not surprisingly, our data showed that the subjective severity of the symptoms was correlated with the utilization of medical resources. A few points need to be discussed here. Firstly, in the present population, a rather large proportion of individuals had undergone upper-gastrointestinal tract endoscopy. This would certainly result in significant costs, which, however, do remain reasonable in Belgium (endoscopy fees range from $€ 100$ to $€ 150$, much lower than in the USA). Moreover, endoscopy has a reassuring effect in about two-thirds of the patients (data not shown), as confirmed recently by a Danish group working with dyspeptic patients [26].

Considering the potential influence of anxiety (shown by our own data) on the severity of the effect of heartburn on daily life, the cost of an early endoscopy must be balanced against its potentially positive effect on subsequent quality of life. Prospective studies could be valuable in evaluating these parameters correctly. Secondly, while numerous patients complained of significant or even severe heartburn, more than $90 \%$ of those being treated were satisfied with their treatment. The majority of the patients rely on simple and cheap treatments, such as antacids, indicating that in most cases the use of more potent drugs (which are also more expensive) is probably 
not necessary. The presence of a small number of unsatisfied patients, however, indicates that some are still treated inadequately and that an effort must be made to tailor treatment to the complaints of the patients.

Finally, as far as symptomatic gastro-oesophageal reflux is concerned, good care and management would seem to imply a compromise between the best possible correction of quality-of-life impairment on the one hand and reasonable and affordable costs on the other. It should be emphasized that, of the individuals in this study who complained that heartburn caused severe disturbance to their daily life, one-fifth had never sought any medical advice and one-fifth did not take any treatment (not even over-the-counter antacids). The use of these simple and inexpensive palliatives should be encouraged for those who seem to lack appropriate care and who may represent up to $1.5 \%$ of the Belgian population.

\section{Acknowledgements}

We would like to thank Patricia Coopmans and Freddy Van de Casseye for their valuable collaboration in the practical organization of this study.

\section{References}

1 Wiklund I, Bardham K, Müller-Lissner S, Bigard M, Bianchi-Porro S, Ponce J, et al. for the European Study group. Quality of life during acute and intermittent treatment of gastroesophageal reflux disease with omeprazole compared with ranitidine. Results from a multicentre clinical trial, Ital J Gastroenterol Hepatol 1998: 30:18-27.

2 Revicki D, Wood M, Maton P, Sørensen S. The impact of gastroesophageal reflux disease on health-related quality of life. Am J Med 1998; 104:252-258.

3 Bruley des Varannes S, Galmiche JP, Bernades P, Bader JP. Douleurs épigastriques et régurgitations. Epidémiologie descriptive dans un échantillon représentatif de la population française adulte. Gastroenterol Clin Biol 1988;12:721-728.

4 Locke GR, Talley NJ, Fett SL, Zinmeister AR. Melton LJ. Prevalence and clinical spectrum of gastro-esophageal reflux: a populationbased study in Olmsted County, Minnesota. Gastroenterology 1997; 112:1443-1456.

5 Glose H. Quality of life and cost of therapy in reflux disease. Scand J Gastroenterol 1995; 210(suppl):38-42.

6 Reflux gastro-oesophagien de l'adulte: 'diagnostic et traitement'. Conclusions et recommandations du jury: texte long. Gastroenterol Clin Biol 1999; 23:56-65.

7 An evidence-based appraisal of reflux disease management The Genval Workshop report. Gut 1999; 44(suppl 2):S1-16.

8 Isolauri J, Laippaia P. Prevalence of symptoms suggestive of gastroesophageal reflux disease in an adult population. Ann Med 1995; 27: $67-70$

9 Ruth M, Mansson I, Sandberg N. The prevalence of symptoms suggestive of esophageal disorders. Scand J Gastroenterol 1991; 26:7381 .

10 Petersen H. The prevalence of gastro-esophagea! reflux disease. Scand J Gastroenterol 1995; 30(suppl 211):5-6.

11 Jones RH, Lydeard SE Hobbs FD, Kenkre JE, Williams EL, Jones SJ, et al. Dyspepsia in England and Scotland. Gut 1990; 31:401 -405.

12 Deltenre M, Cappelle M, Van Wilder Ph, Jonas C, De Koster E Heartburn in Belgium: a population-based epidemiological study. Gastroenterology 1998; 114:A100-101.

13 Klauser AG, Schindlbeck NE, Müller-Lissner SA Symptoms in gastroesophageal reflux disease. Lancet 1990; 335:205-208.

14 Nebel OT, Formes MF, Castell DO. Symptomatic gastro-esophageal reflux; incidence and precipitating factors. Dig Dis Sci 1976; 21 ;953-956.

15 Gallup survey on heartburn across America. Princeton, NJ: The Gallup Organization, Inc.; 1988.

16 Thompson WG, Heaton KW. Heartburn and globus in apparently healthy people. J Can Med Assoc 1982; 128:46-48.

17 DeLOOzE D, Louis E. Regional differences in the perception of gastro oesophageal reflux disease (GORD) in Belgium. Acta Gastroenterol Belg 2000; 63:D32.

18 Kay L. Jorgensen T, Jensen KH. Epidemiology of abdominal symptoms in a random population: prevalence, incidence, and natural history. Eur J Epidemiol 1994; 10:559-566. 
Published in: European Journal of Gastroenterology (2002), vol. 14, pp. 279-284

Status : Postprint (Author's version)

19 Romero Y, Cameron AJ, Locke GR, Schaid DJ, Slezak JM, Branch CD, Melton LJ. Familial aggregation of gastro-esophageal reflux in patients with Barrett's esophagus and esophageal adenocarcinoma. Gastroenterology 1997;113:1449-1456.

20 Dimenäs E. Glise H, Hallerback B, Hemqvist H, Svedlund J, Wiklund I. Quality of life in patients with upper gastrointestinal symptoms. Scand J Gastroenterol 1993; 28:681 -@87.

21 Stacey J, Miocevich M, Sacks G. The effect of ranitidine (as effervescent tablets) on the quality of life of GORD patients. Br J Clin Pract 1998; 50:190-196.

22 Smout A. Endoscopy-negative acid reflux disease. Aliment Pharmacol Ther 1997; 11(suppl 2):81-85.

23 Ringel Y, Sporber AD, Drossman DA. Irritable bowel syndrome. Annv Rev Med 2001; 52:319-338.

24 Castell DO. The lower esophageal sphincter: physiological and clinical aspects. Ann Intern Med 1975; 83:390-401,

25 Kahrilas PJ, Gupta RR. Mechanisms of acid reflux associated with cigarette smoking. Gut 1990; 31:4-10.

26 Lassen AT, Pedersen FM, Bytzer P, Schaffalitzky de Muckadell OB. Helicobacter pylori test-and-eradicats versus prompt endoscopy for management of dyspeptic patients: a randomised trial. Lancet 2000; 366:455-480. 